\title{
Developmental stability, heterozygosity, and fitness in two introduced fire ants (Solenopsis invicta and S. richteri) and their hybrid
}

Kenneth G. Ross and Judith L. Robertson*
Department of Entomology, University of Georgia, Athens, GA 30602, U.S.A.

Fluctuating asymmetry of seven bilateral morphometric characters was studied in two introduced fire ant species, Solenopsis invicta and $S$. richteri, and their hybrid as a means of assessing relative levels of developmental stability. All study populations exhibited significant fluctuating asymmetry for at least three of the seven characters. Among these populations, a hybrid population from Mississippi, U.S.A. exhibited generally high levels of fluctuating asymmetry relative to the parental populations, including a highly significant elevation in asymmetry for one leg character. The $\boldsymbol{S}$. invicta study population generally displayed the lowest levels of fluctuating asymmetry over all characters, as well as the lowest degree of anomalous wing venation. Genomic incompatibility between the parental fire ant species apparently overrides any heterotic effects arising in the regulation of development in the more highly heterozygous hybrids, and thus may create weak selection against hybrid genotypes. Nonetheless, this incompatibility is not of sufficient magnitude to constitute a significant postzygotic isolating mechanism. The dynamic nature and substantial width of the fire ant hybrid zone in the U.S.A may be interpreted as resulting from the interaction of (1) a dominant influx of $\boldsymbol{S}$. invicta alleles from the south associated with superior fitness (greater developmental stability) of this form and (2) a barrier to gene flow between the species caused by weak selection acting against hybrid genotypes.

\section{INTRODUCTION}

Developmental stability is the capacity of organisms to produce well-regulated "average" phenotypes in the face of varying environmental circumstances. Developmental stability as a property of the genetic system has come under increased scrutiny as its relevance to both anagenetic (Dobzhansky, 1970; Palmer, 1986; Clarke and McKenzie, 1987) and cladogenetic (Levin, 1970; Williamson, 1981; Kat, 1982) processes in populations has been realized. Indeed, the apparent association between developmental stability and organismal fitness suggests that its assessment may often reveal much about the relative state of adaptation of populations (Waddington, 1942; Clarke and McKenzie, 1987). Accumulating evidence that higher levels of heterozygosity within species commonly correlate with greater developmental stability, whereas interspecific hybridization frequently leads to its breakdown

\footnotetext{
* Current Address: Maryland Natural Heritage Program, Tawes
} Building B-2, Annapolis, MD 21401, U.S.A. (reviewed in Mitton and Grant, 1984; Palmer and Strobeck, 1986; Ferguson et al., 1988), has given further impetus to the study of genetic factors affecting developmental stability and the role of such factors in micro- and macro-evolutionary processes.

A common means of assessing developmental stability is by analysis of fluctuating asymmetry in bilateral characters. Fluctuating asymmetry is defined as minor random deviations from perfect bilateral symmetry, as evidenced by measurable differences between the right and left sides of single characters on single individuals (Van Valen, 1962). Because both sides of a character are the products of expression of a single genome, such departures from bilateral symmetry presumably reflect the inability of the genome to coordinate development precisely; that is, fluctuating asymmetry reflects non-heritable developmental "noise" (Mather, 1953; Lerner, 1954; Van Valen, 1962; Soulé, 1979, 1982; Leamy, 1984; Leary et al., 1985a; Palmer, 1986). Several studies have suggested that high levels of fluctuating asymmetry are likely to be associated with a decrease in individual fitness 
(Soulé, 1982; Leary et al., 1984, 1985b; Clarke and McKenzie, 1987; see also Brückner, 1976), a result that is expected if developmental stability is an important component of fitness.

In this paper we present the results of a study of fluctuating asymmetry in two fire ants introduced to North America (genus Solenopsis; Hymenoptera: Formicidae) and in hybrid populations formed by these two species. The results are of interest with respect to the effects of both heterozygosity and genomic introgression in the genetic regulation of development and how the interplay of these factors influences the process of hybridization. Solenopsis invicta and $S$. richteri were introduced to the U.S.A. from South America in the early decades of this century. These two species are quite distinct in terms of their genetic make-up at structural (enzyme) loci (Ross et al., $1987 a, b ;$ K. Ross and J. Trager, unpublished), external morphology (Buren, 1972; J. Trager, unpublished), and venom and hydrocarbon biochemistry (Vander Meer et al., 1985; Ross et al., $1987 \mathrm{~b}$ ), yet they have formed an extensive zone of hybridization in the south-central U.S.A. (see fig. 1; Diffie et al., 1988). Given their considerable differentiation for the above traits, it is of interest to determine to what extent $S$. invicta and $S$. richteri have diverged in terms of genomic elements coordinating development. If significant, such divergence may be expected to lead to increased levels of fluctuating asymmetry in hybrid populations relative to the parental species due to disruption of genomic coadaptation (Vrijenhoek and Lerman, 1982; Graham and Felley, 1985; Leary et al., $1985 b)$. On the other hand, if the parental genomes integrate sufficiently well in their regulatory functions then heterotic effects associated with the higher levels of heterozygosity characterizing hybrids may lead to greater developmental stability and lower fluctuating asymmetry in these populations compared to the parental species.

The level of genomic compatibility between $S$. invicta and $S$. richteri in the regulation of development is of particular importance because of its relationship to hybrid fitness and factors mediating introgression. Competing theories of hybrid zone establishment following secondary contact differ largely on the basis of how selection acting on hybrid individuals is defined, that is, whether hybrid fitness should be considered to be inferior,

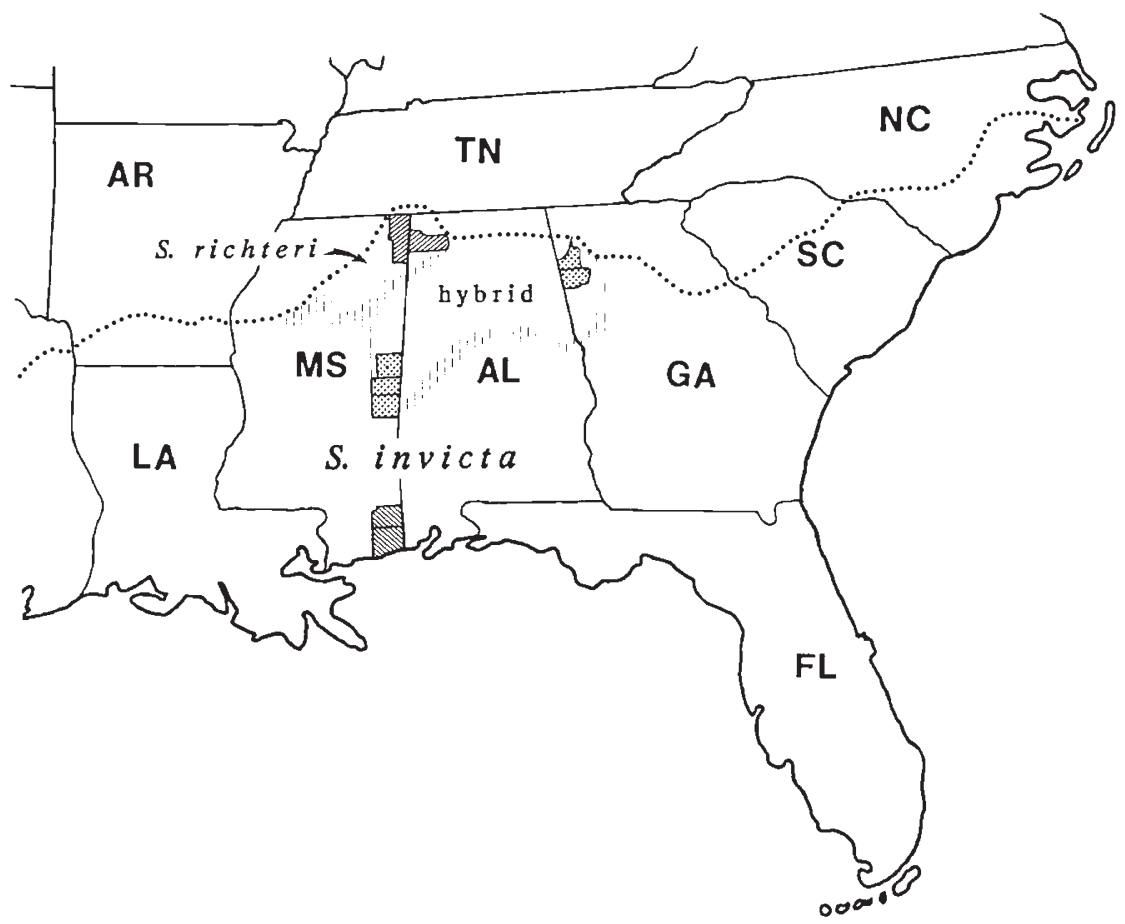

Figure 1 Approximate ranges of introduced fire ants in the U.S.A. (modified from Diffie et al., 1988) and locations of counties from which samples for this study were collected. The dotted line indicates the approximate northernmost extension of introduced populations and the vertical shading delimits the approximate parental species and hybrid ranges. Counties in which hybrid specimens were collected are indicated by stippling, those in which the parental species were collected are indicated by diagonal lines. 
superior, or equivalent to that of the parental forms (Moore, 1977; Hafner et al., 1983; Barton and Hewitt, 1985). If a reduction in developmental stability accompanies introgression then it is reasonable to conclude that hybrids suffer some loss of fitness compared to the parental taxa. This comparative study of levels of fluctuating asymmetry is thus intended to shed some light on the factors responsible for the maintenance and structure of the hybrid zone formed by introduced fire ants in the southern U.S.A.

\section{MATERIALS AND METHODS}

\section{Sample collection and characters}

Samples of hybrid ants were collected from two widely-separated localities, one in east-central Mississippi (Lauderdale, Kemper, and Noxubee Cos.) and one in northwestern Georgia (Floyd and Polk Cos.) (see fig. 1; also Ross et al., 1987b; Diffie et al., 1988). Populations at these locations previously have been shown to be thoroughly introgressed, the Mississippi population to the extent that it is almost exactly intermediate to the parental species in terms of allele frequencies at diagnostic enzyme loci (Ross et al., 1987b). Samples of $S$. richteri were collected from the restricted range occupied by this species in the U.S.A. (from Colbert Co., AL and Tishomingo Co., MS), which lies due north of the Mississippi hybrid collection site (Buren et al., 1974; Vander Meer et al., 1985; Ross et al., 1987b). Solenopsis invicta (monogyne form) was sampled from southeastern Mississippi (Jackson and George Cos.), to the south of the Mississippi hybrid locality. The parental samples are thus intended to be representative of source populations for the influx of parental genes into the Mississippi hybrid population. Several mature alate females were collected from each of 43 colonies of $S$. invicta, from 44 colonies of $S$. richteri, and from 29 colonies in each of the hybrid populations. Specimens were cooled upon collection and subsequently transported on liquid nitrogen to the laboratory, where they were held at $-60^{\circ} \mathrm{C}$ until measurement of characters or electrophoresis. Voucher specimens are deposited in the Entomology Museum of the University of Georgia.

Alate females were chosen for study of fluctuating asymmetry (FA) to minimize possible confounding effects of allometry (likely to be significant for workers) and to provide characters of the wing venation. Seven bilateral metric characters were chosen for study. Three of these charac- ters are found on the forewing: the radial cell (length measured along the subcosta + radius vein from the median axillary sclerite to the first radial sector); the cell Radius 1 (length measured from the point where the first radial sector joins the radial sector fusion with median vein to the point where the radial vein joins the radial sector); and the medio-cubital crossvein (see Ross (1936) and Brown and Nutting (1949) for nomenclature of the forewing cells and veins). The remaining four characters are distributed on three other appendages: the antennal scape; the prothoracic tibia (prothoracic leg); and the metathoracic femur and metathoracic basitarsus (metathoracic leg). No discrete (meristic) characters were judged to be satisfactory for analysis of FA because of unreliability of counts. The length of each character on each side was determined using the ocular micrometer of a dissection microscope. In order to quantify measurement error, repeat measurements were made on the day following initial measurements. Because of the high genetic relatedness (correlation of genotypes) of nestmate females (Ross and Fletcher, 1985a; Ross et al., 1988), only a single female per nest was used for the morphometric analyses.

\section{Analysis of fluctuating asymmetry}

Procedures for analysis were adopted from Palmer and Strobeck (1986). Distributions of the size of each character $\left(\left[R_{\mathrm{i}}+L_{\mathrm{i}}\right] / 2\right.$, where $R_{\mathrm{i}}$ and $L_{\mathrm{i}}$ represent the length of the character on the right and left side of a single individual) were compared among the four study populations. Consistent and significant size differences occurred among the populations (table 1), suggesting that the FA estimates might be biased in the absence of scaling of the character values by some measure of size (e.g., Soulé, 1967; Palmer and Strobeck, 1986). Size dependency of FA both within and among populations was thus assessed by examining plots of $\left|R_{\mathrm{i}}-L_{\mathrm{i}}\right|$ versus character size $\left(\left[R_{\mathrm{i}}+L_{\mathrm{i}}\right] / 2\right)$ and testing for significance by regression analysis of both $\left|R_{\mathrm{i}}-L_{\mathrm{i}}\right|$ and its logarithm against size (done independently for the repeat measurements). For three of the characters (cell Radius 1, metathoracic femur, and metathoracic basitarsus), no size dependency was detected within populations or for data pooled across populations. For the remaining characters significant regressions were obtained for one or more of the populations. This dependency of FA on size within populations was scaled out by transforming the $R_{\mathrm{i}}$ ar.d $L_{\mathrm{i}}$ values for these characters, either by dividing by 
Table 1 Mean character sizes (in $\mathrm{mm}$ ) for four Solenopsis study populations (first set of repeat measurements only, standard deviations in parentheses). Sizes vary significantly among the populations for all characters (Kruskal-Wallis test, all $P<0 \cdot 001$ ); populations with the same letters next to the mean values do not differ significantly at the 0.05 level (Tukey's multiple range test).

\begin{tabular}{|c|c|c|c|c|c|c|c|}
\hline & RADCELL & CELLRA1 & MECVEIN & ANTSCAPE & PROTIB & METFEM & METBTAR \\
\hline S. invicta & $\begin{array}{c}2.374^{\mathrm{a}} \\
(0.056)\end{array}$ & $\begin{array}{r}1.331^{a} \\
(0.036)\end{array}$ & $\begin{array}{c}0.388^{\mathrm{a}} \\
(0.017)\end{array}$ & $\begin{array}{c}0.952^{a} \\
(0.018)\end{array}$ & $\begin{array}{r}0.961^{a} \\
(0.018)\end{array}$ & $\begin{array}{r}1 \cdot 349^{\mathrm{a}} \\
(0.020)\end{array}$ & $\begin{array}{c}1 \cdot 110^{\mathrm{a}} \\
(0 \cdot 019)\end{array}$ \\
\hline MS hybrid & $\begin{array}{c}2.471^{b} \\
(0.071)\end{array}$ & $\begin{array}{l}1 \cdot 344^{\mathrm{ab}} \\
(0.040)\end{array}$ & $\begin{array}{c}0.409^{b} \\
(0.026)\end{array}$ & $\begin{array}{c}0.983^{b} \\
(0.025)\end{array}$ & $\begin{array}{c}0.989^{\mathrm{b}} \\
(0.022)\end{array}$ & $\begin{array}{c}1.382^{b} \\
(0.029)\end{array}$ & $\begin{array}{c}1 \cdot 145^{b} \\
(0.026)\end{array}$ \\
\hline GA hybrid & $\begin{array}{c}2.460^{b} \\
(0.081)\end{array}$ & $\begin{array}{c}1 \cdot 364^{b} \\
(0.043)\end{array}$ & $\begin{array}{r}0.432^{\mathrm{c}} \\
(0.026)\end{array}$ & $\begin{array}{c}0.974^{b} \\
(0.025)\end{array}$ & $\begin{array}{c}0.978^{b} \\
(0.023)\end{array}$ & $\begin{array}{c}1.369^{b} \\
(0.024)\end{array}$ & $\begin{array}{c}1.132^{b} \\
(0.032)\end{array}$ \\
\hline S. richteri & $\begin{array}{r}2 \cdot 557^{\mathrm{c}} \\
(0.049)\end{array}$ & $\begin{array}{c}1.421^{\mathrm{c}} \\
(0.030)\end{array}$ & $\begin{array}{r}0.440^{c} \\
(0.019)\end{array}$ & $\begin{array}{c}1.006^{\mathrm{c}} \\
(0.019)\end{array}$ & $\begin{array}{r}1.012^{\mathrm{c}} \\
(0.019)\end{array}$ & $\begin{array}{r}1.419^{c} \\
(0.024)\end{array}$ & $\begin{array}{r}1.175^{\mathrm{c}} \\
(0.022)\end{array}$ \\
\hline
\end{tabular}

RADCELL = radial cell, CELLRA1 = cell Radius 1, MECVEIN $=$ medio-cubital crossvein, ANTSCAPE $=$ antennal scape, PROTIB = prothoracic tibia, METFEM = metathoracic femur, METBTAR = metathoracic basitarsus .

$\left(R_{\mathrm{i}}+L_{\mathrm{i}}\right) / 2$ or, if this proved unsatisfactory, by the cube of this value.

Character values (untransformed or transformed as appropriate) were used in a two-way, mixed model analysis of variance (ANOVA) to assess fluctuating asymmetry (Palmer and Strobeck, 1986). In this model the two factors are "individuals" (random) and "sides" (fixed), the dependent variable is character length, and repeated measurements are treated as observations within cells. Sources of variance include measurement error $\left(\sigma_{m}^{2}\right)$, variance components arising from nondirectional asymmetry $\left(\sigma_{i}^{2}=\right.$ antisymmetry + fluctuating asymmetry), a random variance component corresponding to individual variability in character size $\left(\sigma_{j}^{2}\right)$, and a fixed variance component due to directional asymmetry $\left(\alpha^{2}\right)$. Testing of the mean squares due to directional asymmetry $\left(M S_{s}\right.$, main effect $=$ sides $)$ or size variation $\left(M S_{j}\right.$, main effect $=$ individuals) over the interaction term $\left(M S_{s j}\right)$ revealed the significance of the contribution of these factors to the observed variance. The significance of nondirectional asymmetry was determined by subtracting the measurement error from $M S_{s j}$ and dividing by the number (2) of repeat measures (see table 3B in Palmer and Strobeck, $1986)$; the remaining variance component $\left(\sigma_{i}^{2}\right)$ was tested over $\sigma_{m}^{2}$ using the standard $F$-test with the Satterthwaite formula for the degrees of freedom. Significant differences among populations in levels of nondirectional asymmetry $\left(\sigma_{i}^{2}\right)$ were identified using Bartlett's test for homogeneity of variances (degrees of freedom estimated from the Satterthwaite formula), followed by pairwise comparisons using $F$-tests for those characters in which significant differences among populations were revealed. Because of the increased potential for Type I errors with multiple independent pairwise comparisons, a significance level of 0.025 was employed for the latter tests (Daniel, 1978).

Variance stemming from nondirectional asymmetry comprises components due to antisymmetry as well as fluctuating asymmetry, so it is essential to determine whether antisymmetry is of any significance in the study populations. Fluctuating asymmetry is defined as the normal distribution about zero of signed differences between the right and left sides of individuals (Van Valen, 1962). On the other hand, antisymmetry, the routine asymmetrical overdevelopment of a character with equal frequency on either side, is characterized by a bimodal or platykurtic distribution of $R_{\mathrm{i}}-L_{\mathrm{i}}$ values about zero. Thus the distributions of differences between sides for each character in each fire ant population were tested for departures from normality, using the Kolmogorov-Smirnov test with Lilliefors' (1967) correction. Those distributions departing significantly from normality were tested for significant kurtosis using Geary's (1936) procedure for small samples and for significant skewness using the standard coefficient of skewness (Snedecor and Cochran, 1980).

\section{Anomalous wing venation}

In the course of examination of wing venation it became apparent that some ants had extra development of wing veins or were missing whole or parts of veins. Such anomalous wing venation presumably can provide a measure of developmental stability independent of FA, and so these patterns were scored in a subset of ants using a scale reflecting the degree of severity. In this scale extra vein development was scored from "1" (slight bulge) to "4" (obvious spur at least three times as long as the vein width), with missing or incomplete 
veins scored as " 3 ". The score for an individual was the sum of the scores earned on both the right and left wings. Differences among population scores were analyzed using Kruskal-Wallis oneway analysis of variance by ranks, followed by Dunn's non-parametric multiple-comparison test to specify significant pairwise differences (Daniel, 1978).

\section{Genetic analyses}

Electrophoresis was conducted on horizontal starch gels using procedures outlined in Ross et al. $(1987 a)$. Previous studies based on examination of 26 loci (Ross et al., 1987a,b) have shown that five enzyme loci are informative with regard to distinguishing between $S$. invicta and $S$. richteri in the USA (Agp-1, Est-2, Est-4, Gpi, Odh) and that three of these (Est-2, Gpi, Odh) are diagnostic for the two species (they have no alleles in common). The remaining 21 loci show no meaningful variability either between or within the species ( 5 per cent criterion for intraspecific polymorphism). Taxonomic identity of specimens used for morphometric analysis was confirmed by determining the genotypes of seven female nestmates of the specimens at the five informative loci.

To quantify genetic diversity in the four study populations, a single diploid genotype per locus was sampled from each colony which provided a specimen for morphometric analysis. Only one genotype was used in this and the remaining analyses because of the high correlation (i.e., nonindependence) of nestmate genotypes. Observed heterozygosity $\left(H_{\text {obs }}\right.$ ) represents the mean proportion of heterozygotes for the 26 loci studied, whereas expected heterozygosity $\left(H_{\text {exp }},=\right.$ gene diversity) was calculated from the population allele frequencies using equation (8.4) in $\mathrm{Nei}$ (1987). Gene diversity was compared among the populations using paired-sample $t$-tests on the angular-transformed individual locus heterozygosity values (Archie, 1985; Nei, 1987).

Observed genotype proportions in the hybrid populations were compared to those expected under Hardy-Weinberg equilibrium (with Levene's (1949) correction) using classical $\chi^{2}$ goodness-of-fit tests. Because of small sample sizes, the two alleles of Est-2 characterizing $S$. richteri were collapsed into a single class.

Extent of introgression in the two hybrid populations was quantified by calculating an index of hybridization from the mean of the population allele frequencies at the three diagnostic loci. An index value of 0.5 represents exact intermediacy in terms of these allele frequencies, whereas values greater than this indicate a genetic resemblance of a population to $S$. invicta and values less than this a resemblance to $S$. richteri.

\section{RESULTS}

Mean character sizes $\left(\left[R_{\mathrm{i}}+L_{\mathrm{i}}\right] / 2\right)$ varied significantly among the four study populations for all seven characters (table 1 ). In all cases $S$. invicta exhibited the smallest mean value and $S$. richteri the largest, with the two hybrid populations being intermediate in size. For six of the seven characters, the two hybrid populations formed a homogeneous group significantly distinct in size from the parental forms.

Results of the ANOVAs for assessing the sources and nature of asymmetry in the seven characters are presented in tables $2-4$. Individual variation consistently contributed to character size variance (table 2) for those characters in which untransformed values or values divided by the cube of character size were used. However, the absence of any meaningful trend in size dependency following size scaling transformations, as determined by regression analysis, indicates that this individual effect is of little consequence for interpreting levels of fluctuating asymmetry (FA). Directional asymmetry was found to be significant $(0.01<P<0.05)$ in three instances. Two of the significant mean $R_{\mathrm{i}}-L_{\mathrm{i}}$ values were less than zero whereas one was greater, and these cases of directional asymmetry were distributed among three different characters and populations (table 2 , main effects $=$ sides).

The importance of nondirectional asymmetry (FA + antisymmetry) relative to measurement error varied from character to character and among the populations (table 3). All of the populations exhibited significant levels of nondirectional asymmetry of the radial cell (RADCELL), cell Radius 1 (CELLRA1), and prothoracic tibia (PROTIB), whereas no evidence of such asymmetry was found for the antennal scape (ANTSCAPE) in any population. The lowest number of significantly asymmetric characters was found for $S$. invicta (three), followed by the Georgia (GA) hybrid population and $S$. richteri (five). The Mississippi (MS) hybrid population exhibited significant nondirectional asymmetry for six of the seven characters.

Nondirectional asymmetry varied significantly among the four populations only for the metatho acic femur (METFEM) and metathoracic basitarsus (METBTAR) (table 4). For both of these characters the MS hybrid population had the 
Table 2 Values of $F$ for main effects (individuals, sides) mean squares tested over the interaction terms to assess the significance of random size variation among individuals and directional asymmetry in contributing to character size variance

\begin{tabular}{|c|c|c|c|c|c|c|c|}
\hline & RADCELL & CELLRA1 & MECVEIN & ANTSCAPE & PROTIB & METFEM & METBTAR \\
\hline \multicolumn{8}{|l|}{ S. invicta } \\
\hline individuals & 0 & $11 \cdot 2^{* *}$ & $21 \cdot 8^{* *}$ & $54 \cdot 3 * *$ & 0 & $15 \cdot 3^{* *}$ & $26 \cdot 8^{* *}$ \\
\hline sides & $0 \cdot 10$ & $6 \cdot 17^{*}$ & 0.48 & 0.68 & $2 \cdot 89$ & 0 & 1.01 \\
\hline \multicolumn{8}{|l|}{ MS hybrid } \\
\hline individuals & 0 & $24 \cdot 2^{* *}$ & $45 \cdot 6^{* *}$ & $64 \cdot 7^{* *}$ & 0 & $10 \cdot 3 * *$ & $18 \cdot 9^{* *}$ \\
\hline sides & $0 \cdot 18$ & 0.62 & $4 \cdot 20$ & 0.76 & $1 \cdot 62$ & $0 \cdot 17$ & 0.02 \\
\hline \multicolumn{8}{|l|}{ GA hybrid } \\
\hline individuals & 0 & $19 \cdot 0^{* *}$ & $56 \cdot 6^{* *}$ & $113 \cdot 2 * *$ & 0 & $17 \cdot 2^{* *}$ & $37 \cdot 0^{* *}$ \\
\hline sides & $0 \cdot 35$ & 1.45 & $5 \cdot 29^{*}$ & $2 \cdot 13$ & $0 \cdot 15$ & 0.35 & 0.77 \\
\hline \multicolumn{8}{|l|}{ S. richteri } \\
\hline individuals & 0 & $8 \cdot 02^{* *}$ & $23 \cdot 2^{* *}$ & $81 \cdot 8^{* *}$ & 0 & $15 \cdot 4^{* *}$ & $24 \cdot 0^{* *}$ \\
\hline sides & 0.28 & 0.30 & $2 \cdot 33$ & 0.09 & 0.01 & $0 \cdot 31$ & $5 \cdot 46^{*}$ \\
\hline
\end{tabular}

RADCELL = radial cell, CELLRA1 = cell Radius 1, MECVEIN = medio-cubital crossvein, ANTSCAPE = antennal scape, PROTIB = prothoracic tibia, METFEM = metathoracic femur, METBTAR = metathoracic basitarsus

* $P<0.05$.

$* * P<0.01$

Table 3 Values of $F$ for variance due to nondirectional asymmetry $\left(\sigma_{i}^{2}\right)$ tested over measurement error $\left(\sigma_{m}^{2}\right)$. Measurement error as a proportion of nondirectional asymmetry (inverse of $F$ ) is shown in parentheses

\begin{tabular}{|c|c|c|c|c|c|c|c|}
\hline & RADCELL & CELLRA1 & MECVEIN & ANTSCAPE & PROTIB & METFEM & METBTAR \\
\hline S. invicta & $\begin{array}{l}2 \cdot 56^{* *} \\
(0.39)\end{array}$ & $\begin{array}{l}4 \cdot 62^{* *} \\
(0 \cdot 22)\end{array}$ & $\begin{array}{c}1.44 \\
(0.69)\end{array}$ & $\begin{array}{c}0 \cdot 41 \\
(2 \cdot 44)\end{array}$ & $\begin{array}{c}4 \cdot 45^{* *} \\
(0 \cdot 23)\end{array}$ & $\begin{array}{c}1.05 \\
(0.95)\end{array}$ & $\begin{array}{c}0.96 \\
(1.04)\end{array}$ \\
\hline MS hybrid & $\begin{array}{l}2 \cdot 61^{* *} \\
(0 \cdot 38)\end{array}$ & $\begin{array}{l}3 \cdot 55^{* *} \\
(0 \cdot 28)\end{array}$ & $\begin{array}{l}3 \cdot 85^{* *} \\
(0 \cdot 26)\end{array}$ & $\begin{array}{c}1 \cdot 19 \\
(0 \cdot 84)\end{array}$ & $\begin{array}{l}6 \cdot 41^{* *} \\
(0 \cdot 16)\end{array}$ & $\begin{array}{l}6 \cdot 86^{* *} \\
(0 \cdot 15)\end{array}$ & $\begin{array}{l}3 \cdot 55^{* *} \\
(0 \cdot 28)\end{array}$ \\
\hline GA hybrid & $\begin{array}{l}3 \cdot 27^{* *} \\
(0 \cdot 31)\end{array}$ & $\begin{array}{l}3 \cdot 37^{* *} \\
(0 \cdot 30)\end{array}$ & $\begin{array}{c}1 \cdot 20 \\
(0.83)\end{array}$ & $\begin{array}{c}0 \cdot 18 \\
(5 \cdot 56)\end{array}$ & $\begin{array}{l}3 \cdot 35^{* *} \\
(0 \cdot 30)\end{array}$ & $\begin{array}{c}2 \cdot 04^{*} \\
(0.49)\end{array}$ & $\begin{array}{l}2 \cdot 83^{* *} \\
(0.35)\end{array}$ \\
\hline S. richteri & $\begin{array}{c}9 \cdot 40^{* *} \\
(0 \cdot 11)\end{array}$ & $\begin{array}{l}5 \cdot 84^{* *} \\
(0 \cdot 17)\end{array}$ & $\begin{array}{c}3 \cdot 50^{* *} \\
(0.29)\end{array}$ & $\begin{array}{c}0 \cdot 74 \\
(1 \cdot 35)\end{array}$ & $\begin{array}{c}9 \cdot 31^{* *} \\
(0 \cdot 11)\end{array}$ & $\begin{array}{l}2 \cdot 53^{* *} \\
(0 \cdot 40)\end{array}$ & $\begin{array}{c}1.59 \\
(0.63)\end{array}$ \\
\hline
\end{tabular}

RADCELL = radial cell, CELLRA1 = cell Radius 1, MECVEIN = medio-cubital crossvein, ANTSCAPE = antennal scape, PROTIB = prothoracic tibia, METFEM = metathoracic femur, METBTAR = metathoracic basitarsus.

* $P<0.05$.

** $P<0 \cdot 01$

Table 4 Variance in character size due to nondirectional asymmetry $\left(\sigma_{i}^{2}\right)$, normalized for each character to the largest value among the four study populations. Variance is significantly heterogeneous among the populations for METFEM and METBTAR (Bartlett's test); for these two characters populations with the same letters next to the values do not differ significantly at the 0.025 level (pairwise $F$-tests).

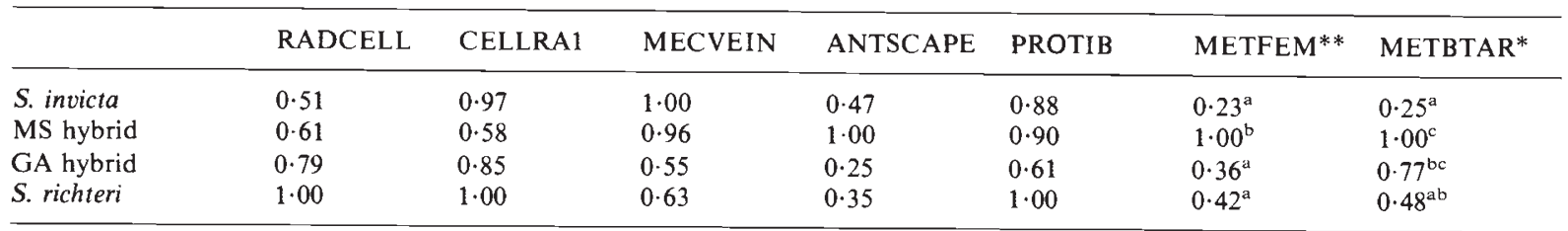

RADCELL = radial cell, CELLRA1 = cell Radius 1, MECVEIN = medio-cubital crossvein, ANTSCAPE = antennal scape, PROTIB = prothoracic tibia, METFEM = metathoracic femur, METBTAR = metathoracic basitarsus.

$* P<0.025$.

** $P<0.01$. 
greatest nondirectional asymmetry, which for METFEM was significantly distinct from that of the remaining populations. Significance patterns were more complex for METBTAR; however, $S$. invicta and the MS hybrid population represent the extreme values linked statistically to only a single most similar population (the hybrid populations are linked by virtue of their high values). Because somewhat similar results were obtained for these two significant characters and because they are found on the same appendage, the potential problem of their non-independence arises. However, correlation analysis of $\left|R_{\mathrm{i}}-L_{\mathrm{i}}\right|$ for individual populations as well as the pooled data failed to reveal any significant positive associations between the characters (Pearson product-moment correlations, all $P>0 \cdot 10, N=10$ tests), suggesting that their patterns of nondirectional asymmetry may be regarded as independent.

In order to judge whether the nondirectional asymmetry revealed by analysis or variance stems from fluctuating asymmetry of antisymmetry (or some combination of the two), the distributions of individual $R_{\mathrm{i}}-L_{\mathrm{i}}$ values were studied. Of the 28 possible character by population combinations, only two (7.1 per cent) diverged significantly from normality $(P<0.05)$ for both sets of repeat measurements. In the MS hybrid population, leptokurtosis (a relatively narrow peak of values) contributed to the departure from normality for the PROTIB distributions, whereas both leptokurtosis and negative skewness were implicated for METFEM in the GA hybrid population. The absence of any evidence for platykurtosis suggests that the nondirectional asymmetry observed in this study consists largely or wholly of fluctuating asymmetry, rather than antisymmetry (Palmer and Strobeck, 1986).

Comparison of scores for anomalous wing venation revealed significant differences among the study populations (Kruskal-Wallis test, $P<$ $0 \cdot 005)$. Solenopsis invicta exhibited the lowest overall level of anomalous venation, linked statistically only to the GA hybrid population (table 5). Levels of anomalous venation are statistically indistinguishable among $S$. richteri and the two hybrid populations.

Genetic data from the nestmates of individuals used for morphometric analysis provide estimates of levels of genetic variability in the study populations (table 6). As expected given that (1) the parental populations are fixed for alternate alleles at three loci, and (2) no evidence for large-scale departure from panmixis has been found (Ross et $a l ., 1987 a, b$; see also below), the hybrid popula-
Table 5 Means of the ranks of scores for anomalous wing venation in four Solenopsis study populations (higher rank values signify greater amounts of anomalous venation). Populations with the same letters next to the values do not differ significantly using the $\alpha=0.15$ experimentwise error rate (Dunn's multiple-comparison test).

\begin{tabular}{ll} 
& $\bar{R}_{i}$ \\
\hline S. invicta $(N=28)$ & $34 \cdot 1^{\mathrm{b}}$ \\
MS hybrid $(N=23)$ & $54 \cdot 6^{\mathrm{a}}$ \\
GA hybrid $(N=15)$ & $44 \cdot 3^{\mathrm{ab}}$ \\
S. richteri $(N=32)$ & $61 \cdot 8^{\mathrm{a}}$ \\
\hline
\end{tabular}

Table 6 Proportion of polymorphic loci ( $P, 5$ per cent criterion), average observed heterozygosity per locus $\left(H_{\mathrm{obs}}\right)$, and expected heterozygosity $\left(H_{\mathrm{exp}}\right.$, gene diversity) for four Solenopsis study populations. Populations with the same letters next to the values for $H_{\exp }$ do not differ significantly in heterozygosity at the 0.05 level ( 1 -tail probability, paired-sample $t$-tests).

\begin{tabular}{llll}
\hline & $P$ & $H_{\text {obs }}$ & $H_{\text {exp }}$ \\
\hline S. invicta & 0.077 & 0.037 & $0.038^{\mathrm{ab}}$ \\
MS hybrid & 0.192 & 0.078 & $0.080^{\mathrm{bc}}$ \\
GA Hybrid & 0.192 & 0.072 & $0.078^{\mathrm{c}}$ \\
S. richteri & 0.038 & 0.019 & $0.019^{\mathrm{a}}$ \\
\hline
\end{tabular}

tions have a higher proportion of polymorphic loci than do the parental populations, as well as generally higher levels of heterozygosity $(P=0 \cdot 065$ for the comparison between $S$. invicta and the MS hybrid population). Heterozygosity values for $S$. invicta and $S$. richteri are virtually identical to earlier estimates based on more complete samples (Ross et al., 1987a).

The index of hybridization value calculated from the allele frequencies at diagnostic loci is 0.50 for the MS hybrid population, whereas that for the GA population is 0.62 . Thus both populations are thoroughly introgressed, although the MS population appears to be relatively more so. The GA population is more similar genetically to $S$. invicta than to $S$. richteri, based on the consistent overrepresentation in this population of diagnostic $S$. invicta alleles. Genotype proportions at all polymorphic loci in both hybrid populations agree well with Hardy-Weinberg expectations ( $\chi^{2}$ test, all $P>0 \cdot 10, N=10$ tests), thus validating the use of an index based on population allele frequencies to estimate extent of introgression.

\section{DISCUSSION}

Our results show that significant levels of fluctuating asymmetry (FA) characterize the study popula- 
tions for a minimum of three of the seven characters, with all populations except $S$. invicta exhibiting significant FA for five or six characters. These significant levels of FA may reflect reduced heterozygosity stemming from founder effects associated with the recent colonization of the southern U.S.A. by these ants (Ross and Fletcher, $1985 b$; see also Vrijenhoek and Lerman, 1982; Wayne et al., 1986). Alternatively, these findings may represent a more general feature of natural populations of social Hymenoptera. A growing body of data indicates that these insects (including native Solenopsis) are relatively deficient in genetic variability (and thus heterozygosity) as determined electrophoretically (Graur, 1985; Sheppard and Heydon, 1986; Ross et al., 1987 a; K. Ross and J. Trager, unpublished), and a decreased capacity for genetic buffering of development may accompany this low heterozygosity if such buffering is achieved largely via overdominance. Comparative surveys of fluctuating asymmetry in other social Hymenoptera will be required in order to address this issue.

Levels of fluctuating asymmetry vary significantly among the fire ant study populations for only two of seven characters; for both of these characters the MS hybrid population exhibits the highest levels. Whereas FA in the MS hybrid population is statistically distinct from that in the remaining populations for the character METFEM, for METBTAR there is suggestive evidence that both hybrid populations may express significantly elevated FA. Over all characters, $S$. invicta had the lowest number of significant FA values (three), whereas the MS hybrid population had the greatest (six). From these results it appears that the MS hybrid population exhibits a modest elevation in FA relative to the other populations and that $S$. invicta generally has the lowest levels of FA.

How are these data to be interpreted in light of our present knowledge of the population biology and genetics of these ants? First, there is no evidence to indicate that increased heterozygosity per se, as manifested in the hybrid populations, is capable of enhancing developmental stability, a finding which has also emerged from other studies of interspecific hybridization (Graham and Felley, 1985; Leary et al., 1985b). Indeed, the evidence for increased FA in at least one of the hybrid populations suggests that incompatibilities in the regulatory elements of the parental genomes compromise the capacity for genetic buffering of development in hybrids in spite of their increased heterozygosity (see also Dobzhansky, 1970; Vrijen- hoek and Lerman, 1982; Graham and Felley, 1985; Leary et al., 1985b). It is of significance in this regard that the MS hybrid population appears to be more completely introgressed than the GA population, and it is in the former population that elevated FA was most apparent.

The modest detectable increase in FA in hybrid fire ants suggests relatively minor divergence between the regulatory genes of the parental forms as reflected in their ability to integrate successfully in the coordination of development. This modest incompatibility at the regulatory level appears to compare favorably with the moderate divergence observed between $S$. invicta and $S$. richteri at the structural gene level, for example at enzyme loci (Nei's genetic distance $[D]=0.176$ for U.S.A. populations and $0 \cdot 105$ for Argentine populations; Ross et al., 1987a; K. Ross and J. Trager, unpublished). However, data on hybrid viability or developmental stability from other ants are not available to provide a framework of reference for meaningfully comparing rates of regulatory and structural gene evolution in this group, as has been possible with some fishes and Drosophila (e.g., Parker et al., 1985; Ferguson et al., 1988; Coyne and Orr, 1989). Perhaps the most important point to be made regarding genomic incompatibility between $S$. invicta and $S$. richteri is that it is certainly too slight to serve as an effective postzygotic isolating mechanism between the two species, as is also suggested by the considerable width and genetic structure of the hybrid zone in the U.S.A. (see below). The absence of effective postzygotic isolating mechanisms is of interest in view of the fact that $S$. invicta and $S$. richteri maintain their genetic distinctiveness over their native ranges in Argentina, even in areas of parapatry (K. Ross and J. Trager, unpublished). These observations suggest that prezygotic barriers are of primary importance in preserving genetic isolation in the native habitats of these ants.

The extent of genomic compatibility between $S$. invicta and $S$. richteri is relevant to understanding the forces mediating hybridization between the two species in the U.S.A., particularly with regard to the configuration of the hybrid zone and its dynamic nature. Both species of fire ants apparently were introduced to the U.S.A. through the port of Mobile in southernmost Alabama (Lofgren et al., 1975; Lofgren, 1986), S. richteri prior to 1920 and $S$. invicta one or two decades later. Hybridization ensued soon thereafter, judging from biochemical analyses of specimens collected from this area in 1949 (R. Vander Meer, C. Lofgren, and E. Wilson, unpublished). At present an exten- 
sive zone of hybridization reaches from eastcentral Mississippi to northwestern Georgia (see fig. 1; Diffie et al., 1988). However, the populations presently occupying southernmost Mississippi and Alabama, where hybrids formerly were found, have now been shown by several methods to comprise genetically "pure" S. invicta (Ross et al., $1987 \mathrm{~b}$ ). Thus the salient features of the fire ant hybrid zone requiring explanation are its substantial width (relative to natural dispersal distances) and its northward displacement in Mississippi and Alabama.

Models of hybridization in continuous habitats have been reviewed by Barton and Hewitt (1985), Littlejohn and Watson (1985), and Moore and Buchanan (1985). These models may be grouped into two classes, depending on whether or not dispersal from the parental populations plays a role in maintaining a hybrid zone. In the dispersalindependent model of "bounded hybrid superiority", the superior fitness of hybrids relative to the parental forms in ecologically intermediate areas results in the formation of spatially stable, self-perpetuating hybrid populations (Moore, 1977; Moore and Buchanan, 1985). Among the dispersal-dependent models, the model of "dynamic equilibrium" applies to hybrid zones sustained by a balance between the opposing forces of gene flow (influx of parental alleles) and selection against hybrids acting as a barrier to gene flow (Barton and Hewitt, 1985). In the event that there is no negative selection on hybrids to impede gene flow then complete "neutral introgression" should follow secondary contact, unless superior fitness of one of the parental forms gives it a competitive advantage over the other, leading to a "wave of advance" of the fitter genotypes. Even if selection against hybrids does restrict gene flow, higher population densities or dispersal rates of a competitively favoured parental form may nonetheless propel a hybrid zone toward the inferior competitor (Barton, 1979a; Barton and Hewitt, 1985).

The significant rate of northward movement of the fire ant hybrid zone, as well as the coincidence of several enzyme gene clines in east-central Mississippi (Ross et al., 1987 b), suggest that dispersal is an important factor mediating hybridization in this region. However, this clearly cannot be characterized as a situation of simple neutral introgression, in which case progressively decaying clines would be generated at the point where contact was first established, well south of the presentday zone. The modest but significant increase in fluctuating asymmetry found for the MS hybrid population suggests some breakdown of develop- mental stability in this introgressed population, which may signal a commensurate reduction in fitness of hybrid genotypes relative to the parental forms. Such selection acting against hybrids would generate a weak barrier to gene flow between $S$. invicta and $S$. richteri, in accord with the expectations of the dynamic equilibrium model. The relatively low levels of FA and anomalous wing venation observed for $S$. invicta may reflect some fitness advantage to genotypes of this parental form, in which case the northward movement of the hybrid zone may be a response to higher population densities in, and thus a greater net influx of alleles from $S$. invicta populations to the south.

That any selection acting against hybrids is weak is suggested not only by the modest extent of the increase in FA in hybrid populations, but also by the occurrence of hybrid genotypes in approximate Hardy-Weinberg proportions (Ross et al., $1987 \mathrm{~b}$; this study) and by the substantial width of the hybrid zone relative to the dispersal capabilities of fire ants. Preliminary analysis of the structure of this zone leads to a minimum estimate of its width (using the $0 \cdot 2-0 \cdot 8$ allele frequency gradient criterion; Endler, 1977) of some $120 \mathrm{~km}$ (Ross et al., 1987b). Studies of nuptial flights of these ants have revealed that most females disperse less than $2 \mathrm{~km}$ prior to establishing nests (Markin et al., 1971), and the recent rate of spread of fire ants into previously uninfested areas of northern Georgia via natural and anthropogenic means yields an estimate of dispersal of $5-15 \mathrm{~km}$ per year (generation) (K. Ross and D. Fletcher, unpublished; T. Canerday, unpublished). The strength of selection (s) acting against hybrids when gene flow is important is inferred to be on the order of $\sigma^{2} / w^{2}$, where $\sigma^{2}$ is the variance in dispersal distance and $w$ the width of the zone (Barton, 1979b; Barton and Hewitt, 1985). From the above data (assuming $\sigma^{2}$ is equivalent to the observed rate of spread), the level of selection acting against hybrid fire ants in the Mississippi population is estimated to be only $10^{-3}-10^{-4}$, a selection coefficient which, although small, is not atypical with respect to values which can be derived for a number of other animal hybrid zones (see fig. 3 in Barton and Hewitt, 1985).

In summary, the data presented here are consistent with the view that $S$. invicta and $S$. richteri exhibit a low level of divergence at the regulatory gene level, that this modest incompatibility may provide a weak barrier to gene flow, and that this barrier is spatially unstable by virtue of a relative fitness advantage of $S$. invicta genotypes over the others. Continuing studies of hybrid zone structure 
in the U.S.A. in conjunction with complete data from the source populations in South America will be necessary to further test this scenario.

Acknowledgements We thank A. R. Palmer and D. M. Nickerson for helpful suggestions for the analyses and M. A. Moran for comments on the manuscript. This research was funded by NSF grant BSR-8615238 to the senior author.

\section{REFERENCES}

ARCHIE, J. W. 1985. Statistical analysis of heterozygosity data: independent sample comparisons. Evolution, 39, 623-637.

BARTON, N. H. 1979a. The dynamics of hybrid zones. Heredity, 43, 341-359.

BARTON, N. H. 1979b. Gene flow past a cline. Heredity, 43, 333-339.

BARTON, N. H. AND HEWITT, G. M. 1985. Analysis of hybrid zones. Ann. Rev. Ecol. Syst., 16, 113-148.

BROWN, W. L. AND NUTTING, W. L. 1949. Wing venation and the phylogeny of the Formicidae (Hymenoptera). Trans. Am. Entomol. Soc., 75, 113-132.

BRÜCKNER, D. 1976. The influence of genetic variability on wing symmetry in honeybees (Apis mellifera). Evolution, 30, 100-108.

BUREN, W. F. 1972. Revisionary studies on the taxonomy of the imported fire ants. J. Georgia Entomol. Soc., 7, 1-26.

BUREN, W. F., ALlen, G. E., WHitCOMB, W. H., LENNARTZ, F. E. AND WILliamS, R. N. 1974. Zoogeography of the imported fire ants. J. N.Y. Entomol. Soc., 82, 113-124.

CLARKE, G. M., AND MCKENZIE, J. A. 1987. Developmental stability of insecticide resistant phenotypes in blowfly; a result of canalizing natural selection. Nature, 325, 345-346.

COYNE, J. A. AND ORR, H. A. 1989. Patterns of speciation in Drosophila. Evolution, 43, 362-381.

DANIEL, W. W. 1978. Applied Nonparametric Statistics. Houghton Mifflin, Boston.

DIFFIE, S., VANDER MEER, R. K. AND BASS, M. H. 1988. Discovery of hybrid fire ant populations in Georgia and Alabama. J. Entomol. Sci., 23, 187-191.

DOBZHANSKY, T. 1970. Genetics of the Evolutionary Process. Columbia University Press, New York.

ENDLER, J. A. 1977. Geographic Variation, Speciation, and Clines. Princeton University Press, Princeton, NJ.

FERGUSON, M. M., DANZMANN, R. G. AND ALLENDORF, F. W. 1988. Developmental success of hybrids between two taxa of salmonid fishes with moderate structural gene divergence. Can. J. Zool., 66, 1389-1395.

GEARY, R. C. 1936. Moments of the ratio of the mean deviation to the standard deviation for normal samples. Biometrika, 28, 295-305.

GRAHAM, J. H. AND FELLEY, J. D. 1985. Genomic coadaptation and developmental stability within introgressed populations of Enneacanthus gloriosus and E. obesus (Pisces, Centrarchidae). Evolution, 39, 104-114.

GRAUR, D. 1985. Gene diversity in Hymenoptera. Evolution, $39,190-199$.

HAFNER, J. C., HAFNER, D. J., PATTON, J. L. AND SMITH, M. F. 1983. Contact zones and the genetics of differentiation in the pocket gopher Thomomys bottae (Rodentia: Geomyidae). Syst. Zool., 32, 1-20.
KAT, P. W. 1982. The relationship between heterozygosity for enzyme loci and developmental homeostasis in peripheral populations of aquatic bivalves (Unionidae). Am. Nat., $119,824-832$.

LEAMY, L. 1984. Morphometric studies in inbred and hybrid house mice. V. Directional and fluctuating asymmetry. $\mathrm{Am}$. Nat., 123, 579-593.

LEARY, R. F., ALLENDORF, F. W. AND KNUDSEN, K. L. 1984. Superior developmental stability of heterozygotes at enzyme loci in salmonid fishes. Am. Nat., 124, $540-551$.

LEARY, R. F., ALLENDORF, F. W. AND KNUDSEN, K. L. $1985 b$. Developmental instability and high meristic counts in interspecific hybrids of salmonid fishes. Evolution, 39, 1318 1326.

LEARY, R. F., ALLENDORF, F. W., KNUDSEN, K. L. AND THORGAARD, G. H. 1985a. Heterozygosity and developmental stability in gynogenetic diploid and triploid rainbow trout. Heredity, 54, 219-225.

LERNER, 1. M. 1954. Genetic Homeostasis. Wiley, New York.

LEVENE, H. 1949. On a matching problem arising in genetics. Ann. Math. Stat., 20, 91-94.

LEVIN, D. A. 1970. Developmental instability and evolution in peripheral isolates. Am. Nat., 104, 343-353.

LILLIEFORS, H. W. 1967. On the Kolmogorov-Smirnov test for normality with mean and variance unknown. J. Amer. Stat. Assoc., 62, 399-402.

LITTLEJOHN, M. J. AND WATSON, G. F. 1985. Hybrid zones and homogamy in Australian frogs. Ann. Rev. Ecol. Syst., 16, $85-112$.

LOFGREN, C. S. 1986. History of imported fire ants in the United States. In Lofgren, C. S. and Vander Meer, R. K. (eds) Fire Ants and Leaf-cutting Ants. Westview Press, Boulder, Co., pp. 36-47.

LOFGREN, C. S., BANKS, W. A. AND GLANCEY, B. M. 1975. Biology and control of imported fire ants. Ann. Rev. Entomol., 20, 1-30.

MARKIN, G. P., DILliER, J. H., HILl, S. O., BLUM, M. S. AND HERMANN, H. R. 1971. Nuptial flight and flight ranges of the imported fire ant, Solenopsis saevissima richteri (Hymenoptera: Formicidae). J. Georgia Entomol. Soc., 6, $145-156$.

MATHER, K. 1953. Genetical control of stability in development. Heredity, 7, 297-336.

MItTON, J. B. AND GRANT, M. C. 1984. Associations among protein heterozygosity, growth rate, and developmental homeostasis. Ann. Rev. Ecol. Syst., 15, 479-499.

MOORE, w. S. 1977. An evaluation of narrow hybrid zones in vertebrates. Quart. Rev. Biol., 52, 263-277.

MOORE, W. S. AND BUChANAN, D. B. 1985. Stability of the northern flicker hybrid zone in historical times: implications for adaptive speciation theory. Evolution, 39, 135-151.

NEI, M. 1987. Molecular Evolutionary Genetics. Columbia University Press, New York.

PALMER, A. R. 1986. Inferring relative levels of genetic variability in fossils: the link between heterozygosity and fluctuating asymmetry. Paleobiology, 12, 1-5.

PALMER, A. R. AND STROBECK, C. 1986. Fluctuating asymmetry: measurement, analysis, and patterns. Ann. Rev. Ecol. Syst., 17, 391-421.

PARKER, H. R., PHILIPP, D. P. AND WHITT, G. S. 1985. Relative developmental success of interspecific Lepomis hybrids as an estimate of gene regulatory divergence between species. J. Exper. Zool., 233, 451-466.

ROSS, H. H. 1936. The ancestry and wing venation of the Hymenoptera. Ann. Entomol. Soc. Amer., 29, 99-111. 
ROSS, K. G. AND FLETCHER, D. J. C. $1985 a$. Comparative study of genetic and social structure in two forms of the fire ant, Solenopsis invicta (Hymenoptera: Formicidae). Behav. Ecol. Sociobiol., 17, 349-356.

ROSS, K. G. AND FLETCHER, D. J. C. 1985b. Genetic origin of male diploidy in the fire ant, Solenopsis invicta (Hymenoptera: Formicidae), and its evolutionary significance. Evolution, 39, 888-903.

ROSS, K. G., VANDER MEER, R. K., FLETCHER, D. J. C. AND VARGO, E. L. 1987 b. Biochemical phenotypic and genetic studies of two introduced fire ants and their hybrid (Hymenoptera: Formicidae). Evolution, 41, 280-293.

ROSS, K. G., VARGO, E. L. AND FLETCHER, D. J. C. 1987 a. Comparative biochemical genetics of three fire ant species in North America, with special reference to the two social forms of Solenopsis invicta (Hymenoptera: Formicidae). Evolution, 41, 979-990.

ROSS, K. G., VARGO, E. L. AND FLETCHER, D. J. C. 1988. Colony genetic structure and queen mating frequency in fire ants of the subgenus Solenopsis (Hymenoptera: Formicidae). Biol. J. Linn. Soc., 34, 105-117.

SHEPPARD, W. S. AND HEYDON, S. L. 1986. High levels of genetic variability in three male-haploid species (Hymenoptera: Argidae, Tenthredinidae). Evolution, 40, $1350-1353$.

SNEDECOR, G. W. AND COCHRAN, W. G. 1980. Statistical Methods. Iowa State University Press, Ames, Iowa.
SOULÉ, M. 1967. Phenetics of natural populations. II. Asymmetry and evolution in a lizard. Am. Nat., 101, 141-160.

SOULÉ, M. 1979. Heterozygosity and developmental stability: another look. Evolution, 33, 396-401.

SOULÉ, M. 1982. Allomeric variation. 1. The theory and some consequences. Am. Nat., 120, 751-764.

VANDER MEER, R. K., LOFGREN, C. S. AND ALVAREZ, F. M. 1985. Biochemical evidence for hybridization in fire ants. Florida Entomol., 68, 501-506.

VAN VALEN, L. 1962. A study of fluctuating asymmetry. Evolution, 16, 125-142.

VRIJENHOEK, R. C. AND LERMAN, S. 1982. Heterozygosity and developmental stability under sexual and asexual breeding systems. Evolution, 36, 768-776.

WADDINGTON, C. H. 1942. Canalization of development and the inheritance of acquired characters. Nature, 150, 563565.

WAYNE, R. K., MODI, W. S. AND O'BRIEN, S. J. 1986. Morphological variability and asymmetry in the cheetah (Acinonyx jubatus), a genetically uniform species. Evolution, 40, 7885.

Williamson, P. G. 1981. Palaeontological documentation of speciation in Cenozoic molluscs from Turkana Basin. Nature, 293, 437-443. 